\title{
PRECISION AGRICULTURE AND IRRIGATION: CURRENT U.S. PERSPECTIVES
}

\author{
S. R. Evett, S. A. O'Shaughnessy, M. A. Andrade, W. P. \\ Kustas, M. C. Anderson, H. H. Schomberg, A. Thompson
}

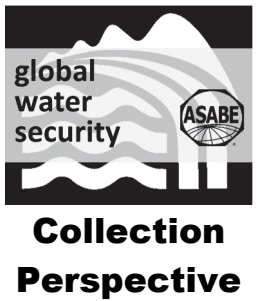

\section{HighLights}

- Precision agriculture (PA) applications in irrigation are stymied by lack of decision support systems.

- Modern PA relies on sensor systems and near real-time feedback for irrigation decision support and control.

- Sophisticated understanding of biophysics and biological systems now guides site-specific irrigation.

- The internet of things (IOT) enables new ways to increase yield per unit of water used and nutrient use efficiency.

Keywords. Crop water productivity, Decision support system, Internet of things, Remote sensing, SCADA, Soil water content.

$\mathrm{T}$ he basic premise of precision agriculture (PA) has been around since the first farmer decided to plant here and not there, to graze this area and not that area, to irrigate this field and not that one, and PA later grew in complexity as farmers selected landraces for specific environments. For example, farmers in West Africa have a wide variety of landraces for sorghum and millet, some of which thrive in the wet lowlands while failing in the dry uplands, and vice versa. Similarly, farmers in the rice lands of Mali in the inland delta of the Niger River have a variety of rice landraces, some adapted to deeper flooding and planting at lower elevations, and some adapted to less or intermittent flooding at the upper edges of the planting areas. Judicious selection and planting of these varieties helps farmers in these regions grow rice successfully without terraforming to create level rice paddies, and it allows considerable rice production despite inter-annual variations in flooding depth.

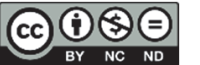

The authors have paid for open access for this article. This work is licensed under a Creative Commons AttributionNonCommercial-NoDerivatives 4.0 International License https://creative commons.org/licenses/by-nc-nd/4.0/

Submitted for review in February 2019 as manuscript number NRES 13355 approved for publication as a Perspective and as part of the Global Water Security Collection by the Natural Resources \& Environmental Systems Community of ASABE in August 2019.

Mention of company or trade names is for description only and does not imply endorsement by the USDA. The USDA is an equal opportunity provider and employer.

The authors are Steven R. Evett, Research Soil Scientist, and Susan A. O'Shaughnessy, Research Agricultural Engineer, USDA-ARS Conservation and Production Research Laboratory, Bushland, Texas, Manuel A. Andrade, Research Agricultural Engineer, Oak Ridge Institute for Science and Education, Sponsored by USDA-ARS Conservation and Production Research Laboratory, Bushland, Texas; William P. Kustas, Research Hydrologist, and Martha C. Anderson, Research Physical Scientist, USDA-ARS Hydrology and Remote Sensing Laboratory, Beltsville, Maryland; Harry H. Schomberg, Research Ecologist, and Alondra Thompson, Agricultural Engineer, USDA-ARS Sustainable Agricultural Systems Laboratory, Beltsville, Maryland. Corresponding author: Steven R. Evett, 300 Simmons Rd., Unit 10, Bushland, TX 79012; phone: 806-356-5775; e-mail: steve.evett@usda.gov.
Site-specific water management likewise found its genesis in the selection of areas for drainage to ameliorate waterlogged soils and in the sizing of fields and basins for irrigation according to the perceived infiltration rates in specific parts of the landscape. Because they create structures that persist over long periods and because the land areas affected are relatively large, these irrigation and drainage design practices are not recognized as PA, even though they are site-specific and often based on precise topographic and geophysical data. Mapping of irrigation systems dates back at least to ancient Babylonia, almost 4,000 years (fig. 1). With the advent of geographic information systems (GIS), global positioning systems (GPS), and modern sensing and irrigation application systems, attitudes about the role of irrigation systems in PA are now changing.

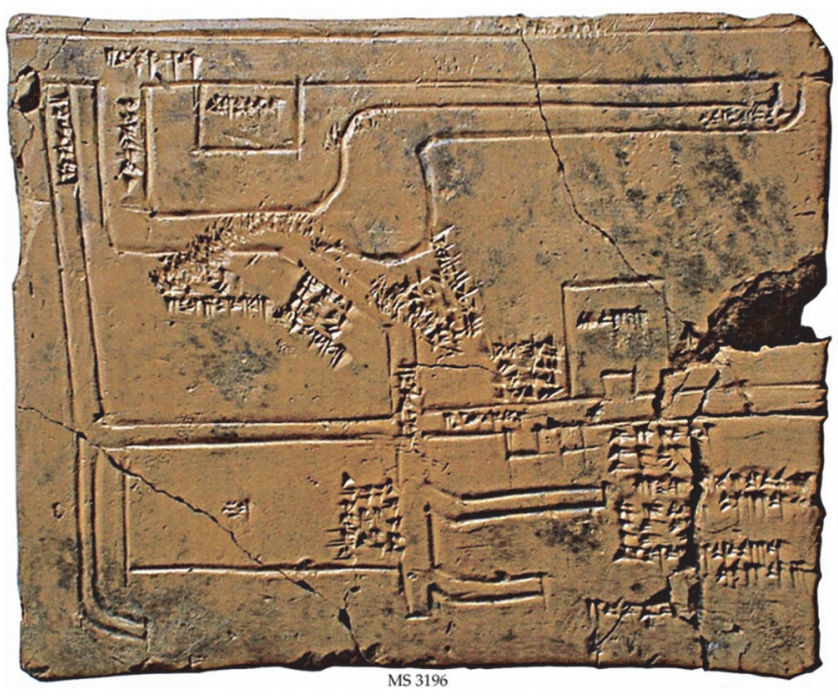

Figure 1. Map on a clay tablet of the canals and irrigation systems west of the Euphrates River showing the canal lengths, widths, and depths. Source: The Schøyen Collection (http://www.schoyencollection.com/ 24-smaller-collections/maps/map-irrigation-ms-3196). 
Modern PA began in the 1980s when GPS became available for public use. Coupled with GIS computer technologies, PA became a mainstream tool for farmers to plan sitespecific operations. Equipment with GPS steering and position-aware supervisory control systems allowed application prescription maps to be downloaded into equipment, for example to turn off a moving irrigation system as it passed over a pre-identified rock outcrop or waterway. GPS-enabled harvesting equipment produced yield maps that were used for site-specific management, often with confusing results due to the lack of co-varying data on soil and landscape properties and the lack of adequate decision support systems (DSS) based on how soil spatiotemporal properties and landscape influence plant development.

Many of the more successful PA technologies involve onboard sensor systems allowing on-the-go adjustments of equipment, for example to turn spray equipment on in the presence of weeds and off otherwise, or to turn on variablerate irrigation nozzles where abiotic stress sensors indicate crop water stress. These supervisory control and data acquisition (SCADA) systems are multiplying rapidly and include systems that automatically thin fruit tree blossoms according to bloom density as a system moves through an orchard. Key to these PA systems are wireless data transmission, wireless sensor networks, and the internet of things (IOT) in which every sensor is a georeferenced node in a larger network, and in which subnetworks are integrated into the internet. Although many successful SCADA systems rely on wireless sensor networks and georeferencing, many are not IOT enabled, although the potential exists. As systems are connected to the internet, issues of data ownership, already extant, become even more prevalent.

Today, the confluence of computing power, data acquisition and management infrastructure, new modeling paradigms, and spatial DSS ushers in new possibilities for PA. Herein we attempt to give a current perspective on the state of modern PA as well as a look at future possibilities and directions, particularly for water management. For example, satellite data, initially not deemed useful for PA due to poor temporal and spatial resolution, are now used in computational systems that fuse data from satellites with different spatial and temporal resolutions and with different spectral imagers to provide daily evapotranspiration maps with $30 \mathrm{~m}$ resolution (Anderson et al., 2018). Providers of PA services now include government institutions, private providers (often using publicly available data from state and federal government on-the-ground, aerial, and satellite sensing systems), university extension systems, and farmer cooperatives. Sources of data range from public domain to private data held by farmers or third parties. Questions about data sharing, data ownership, and public and private rights add further complexity to modern PA. The information technology (IT) sphere now has such importance to PA that some see PA as, "a suite of IT based tools which allow farmers to electronically monitor soil and crop conditions and analyze treatment options" (Aubert et al., 2012).

\section{EXAMPLES OF PRECISION AGRICULTURE}

There are essentially two paradigms for PA: (1) passive and indirect methods in which data are collected and assembled to produce maps of various state variables, which are then used to guide PA, and (2) active and typically direct methods in which sensor subsystems are parts of SCADA systems that process the data and use algorithms to guide the control of machinery for application of inputs and practices. These SCADA systems typically embody a DSS, often one that automatically generates a spatiotemporal prescription for action, which can likewise, but not necessarily, be automatically applied. Examples of the first paradigm include numerous private and public organizations, including large agribusinesses such as Monsanto/Bayer, Cargill, and John Deere, as well as a plethora of smaller businesses. These organizations are involved in collecting high-resolution spatiotemporal data from farms, evaluating the data, and providing value-added services that aim to increase yield, optimize input use, and increase profitability and sustainability through spatially and temporally varying application of agricultural inputs and practices. Data sources may be public or private. Examples of the second paradigm include sensor feedback systems, such as herbicide sprayers, fertilizer application systems, and plant and soil feedback-based irrigation systems, which automatically acquire sensor data, analyze the data to determine actions, and direct machinery to carry out the actions. Data sources in the latter case are nearly universally private.

\section{Prescription Fertilization}

Site-specific fertilizer application was the earliest widely adopted example of PA in the U.S. and typically still follows the passive and indirect paradigm. Presently, the $4 \mathrm{R}$ concept (right source, right rate, right time, and right place) is used to both promote and explain the importance of precision fertilizer management for increased nutrient use efficiency and decreased environmental impact (Sposari and Flis, 2017). In 2016, the USDA Economic Research Service (ERS) reported that nearly half of U.S. corn and soybean growers used GPS yield monitoring, that more than $20 \%$ used yield maps, and that $16 \%$ to $19 \%$ used GPS soil fertility mapping (Schimmelpfennig, 2016). Of these, $20 \%$ used variable-rate fertilization, but this practice was applied on $26 \%$ of corn acres and $34 \%$ of soybean acres, which indicates that adoption was greater on larger farms. Since 2011, yearly surveys of agricultural retail service providers by Purdue University have shown increasing adoption of GPS soil mapping, yield monitoring, and soil bulk electrical conductivity (EC) mapping (Erickson and Lowenberg-Deboer, 2017). Soil sampling with GPS mapping is more highly adopted than other practices and is closely tied to adoption of variable-rate fertilizer application (Griffin et al., 2016); both farmers and dealers report positive returns on investments in PA fertilizer practices and equipment (Erickson and Lowenberg-Deboer, 2017). PA fertilizer practices are most commonly applied to corn, soybean, and wheat in the U.S. (Snyder, 2016).

Despite much research on the use of optical sensors of canopy reflectance for guiding fertilizer applications (e.g., Bronson et al., 2017), this is still considered an advanced and emerging technology that is most often used later in the growing season to guide supplemental fertilizer applications 
(Snyder, 2016). While nitrogen sensors may improve profitability by preventing over- and under-fertilization, the literature reports mixed results (Ondoua and Walsh, 2017). Like other methods, PA nitrogen fertilization guided by sensors fails when something other than nitrogen (most commonly water) is limiting. As with other PA technologies, the availability of precision application equipment outstrips the availability of DSS and the multiple sources of data required to make DSS reliable and to make the outcomes of following DSS-based application prescriptions successful.

\section{Prescription Irrigation}

A recent example of site-specific variable-rate irrigation (VRI) is the Irrigation Scheduling Supervisory Control and Data Acquisition (ISSCADA) system of Evett et al. (2014) (fig. 2). This is an example of the active and direct PA paradigm. Motivated by the rapid increase in pressurized irrigation systems, which cover $65 \%$ of U.S. irrigated lands (USDA, 2014) and are amenable to control, the ISSCADA system is designed to work with linear-move and center-pivot irrigation systems, which cover $57 \%$ of U.S. irrigated lands. The system uses plant sensors mounted on the irriga-tion system lateral to scan plant water stress in the field and produce maps prescribing variable-rate irrigation according to the stress level (O'Shaughnessy et al., 2015).

A subset of sensors is fixed in the field for reference stress sensing, and soil water sensors are buried to provide feedback on irrigation effects in the soil. Data from weather, crop, and soil sensors are automatically and wirelessly collected by an embedded computer at the irrigation system pivot point. Novel algorithms allow conversion of plant stress measurements taken at one time of day in a specific location in the field to a diurnal curve of plant stress, which is then converted to an integrated crop water stress index for the day. This process is repeated for each control zone, producing a map of crop water stress (fig. 3 , left). Control zones may be as small as $2^{\circ}$ of arc, with radial increments defined by adjacent pairs of crop sensors pointing at the control zone from opposite sides (to control for sun angle and sensor zenith angle effects). The crop water stress map is converted into a prescription map defining the irrigation amount for each control zone (fig. 3, right), which can automatically guide the irrigation system or be modified by the irrigation manager before automatic applica-

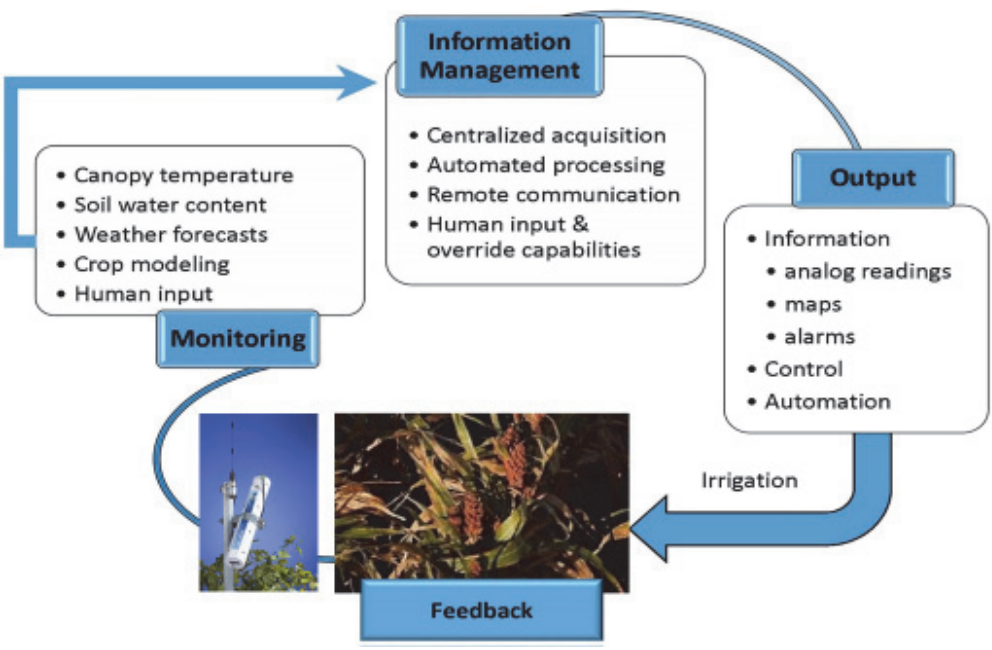

Figure 2. The sensing, information management, prescription mapping, irrigation control, and plant feedback loop for the Irrigation Scheduling Supervisory Control and Data Acquisition (ISSCADA) system that directs a variable-rate, center-pivot irrigation system to apply water when, where, and in the quantity needed.
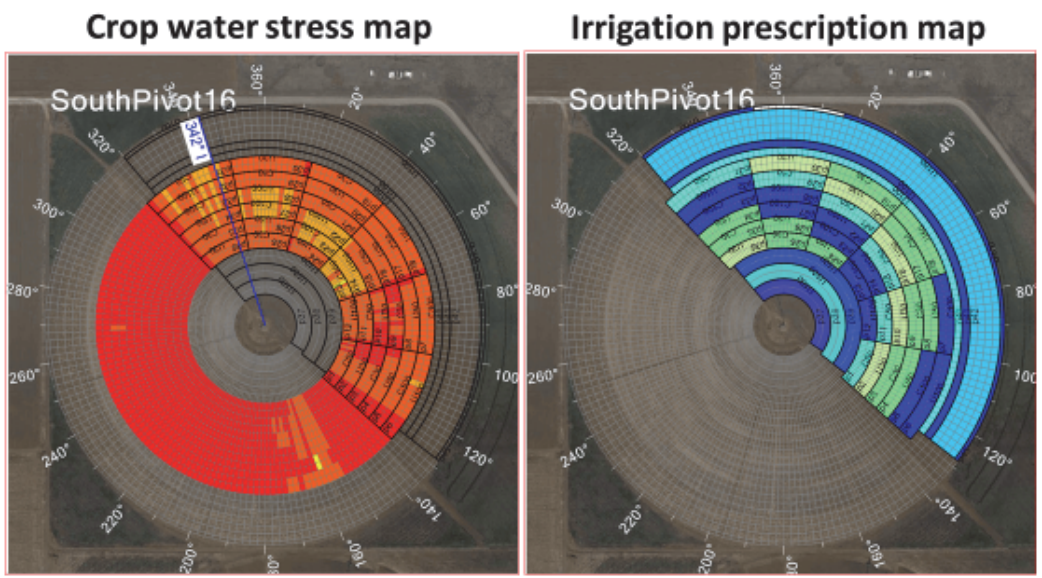

Figure 3. (Left) A crop water stress map produced from canopy temperature data acquired by a wireless infrared thermometer system deployed on a center-pivot irrigation system lateral. The lower left half of the field was fallowed. (Right) An irrigation prescription map automatically produced by the ISSCADA DSS system from the crop water stress data. 
tion. The infrared sensors and sensor network were commercialized from research prototypes (O'Shaughnessy et al., 2013), and the soil water sensors were also developed with a commercial partner (Evett et al., 2015; Schwartz et al., 2016). This amounts to a $3 \mathrm{R}$ concept for irrigation (right place, right amount, and right time) and results in improved crop water productivity for several field crops in the U.S. Great Plains (cotton, maize, sorghum, and soybean) (O'Shaughnessy et al., 2016).

The ISSCADA system puts the PA sensors, IT system, and application equipment in the hands of the producer. Although it can use secondary data such as SSURGO (USDA, 2017) soil mapping units or soil EC maps to fine-tune prescriptions, it does not require them.

A contrasting PA irrigation system is the newly developed "pixelated" irrigation management system used in vineyards in California (Semmens et al., 2015; Xia et al., 2016; Knipper et al., 2018). This system is of the passive and indirect type. Data from multiple satellite remote sensing platforms are fused to produce an ET toolkit of daily, $30 \mathrm{~m}$ pixel maps of evapotranspiration (ET, crop water use) (Anderson et al., 2012, 2018; Cammalleri et al., 2013, 2014) (fig. 4). In trials in California, daily
$30 \mathrm{~m}$ vineyard ET data were used to manage vineyard irrigation systems, reducing spatial variations in crop water status and yield and improving crop quality. Expected operational products of this USDA-ARS/NASA collaboration include datacubes of daily ET at $30 \mathrm{~m}$ resolution for selected growing areas (fig. 4). As part of the NASA-funded Grape Remote sensing Atmospheric Profile and Evapotranspiration Experiment (GRAPEX; Kustas et al. 2018), the USDA-ARS, NASA, and academic researchers are collaborating with E. \& J. Gallo Winery to use these ET datacubes to manage vineyard irrigation systems in California, to determine the start of the irrigation season and weekly irrigation recommendations (fig. 5). Expected outcomes are reductions in total water use and in spatial variations of crop water stress and yield, and simultaneously improved grape quality for wine production. In other collaborations, the USDA-ARS has implemented this ET toolkit for target sites in South Dakota, Maryland, Nebraska, North Carolina, and elsewhere to help solve site-specific water management problems. Examples include corn and soybean in rotation, and winter wheat double-cropped with soybeans in Maryland (Sun et al., 2017), corn and soybean in Nebraska (Yang et al., 2018a), corn and soybean yields as affected by tile drainage in South Dakota

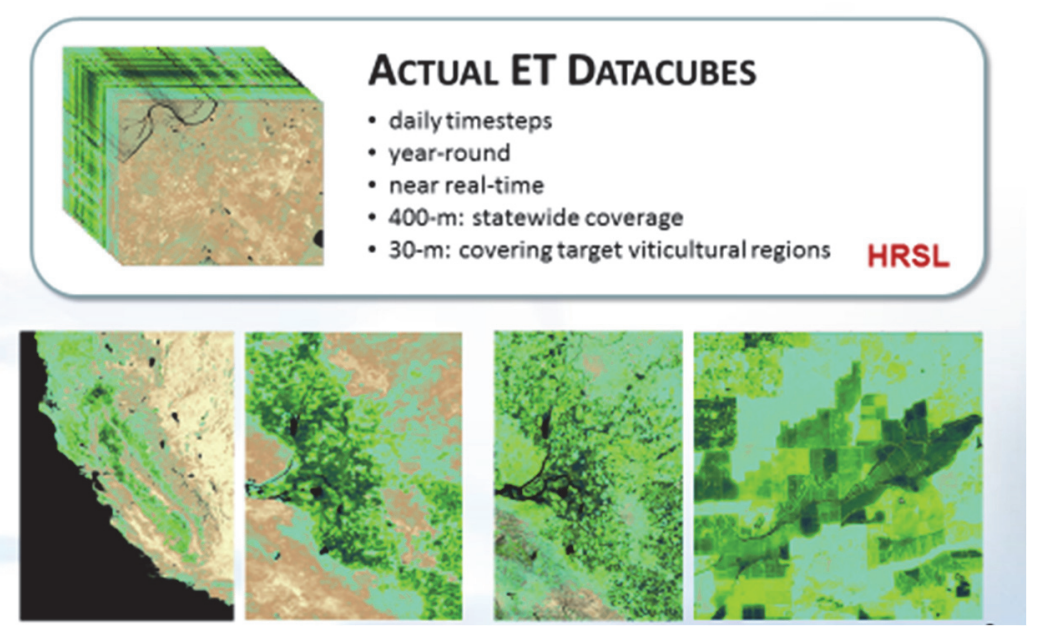

Figure 4. (Top) Characteristics of ET datacubes. (Bottom, left to right) California statewide daily ET image at $400 \mathrm{~m}$ resolution, detail of the California Delta region, detail of the same region at $30 \mathrm{~m}$ resolution, and a closer look at a few vineyards and surrounding fields at $30 \mathrm{~m}$ resolution. From the USDA ARS Hydrology and Remote Sensing Laboratory (HSRL), Beltsville, MD.

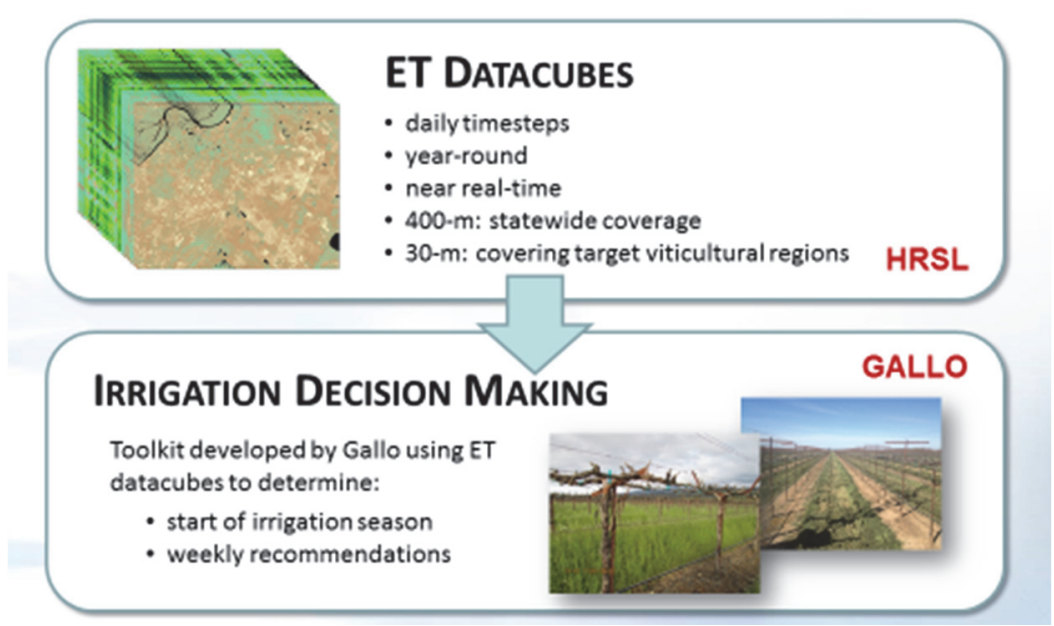

Figure 5. ET datacubes are made available at daily time steps in near real-time and with $\mathbf{3 0} \mathrm{m}$ resolution for targeted growing areas. E. \& J. Gallo Winery has developed a toolkit for using ET datacubes to determine the start of the irrigation season and weekly irrigation recommendations. 
(Yang et al., 2017a), and pine plantations in North Carolina (Yang et al., 2017b, 2018b).

\section{$P A$ for Other Specialty Crops}

Specialty crop production, including grapes, accounts for more than $38 \%$ of U.S. crop value production (USDA, 2015 ), and tree fruit production accounts for $39 \%$ of that production (USDA, 2014). However, specialty crop production is labor-intensive and thus costly, while labor availability varies inter-annually. For example, fruit thinning is one of the most costly steps in production, but it ensures profitable production through optimal fruit size and quality. The same is true for crops such as lettuce, which is why precision planting and thinning systems are increasingly being developed (Lyons et al., 2015) and put into practice in the U.S. (Shearer and Pitla, 2014).

\section{New Paradigms for Precision Agriculture}

The consideration of plant genetics $(\mathrm{G})$, environmental (E) factors, and management $(\mathrm{M})$ practices in research on sustainable farming systems has led to the paradigm of $\mathrm{G} \times$ $\mathrm{E} \times \mathrm{M}$ research (Hatfield and Walthall, 2015), which harkens back to the very beginnings of farmer recognition of environmentally adapted landraces and the management practice of spatial sensitivity in planting them. The $\mathrm{G} \times \mathrm{E} \times \mathrm{M}$ paradigm also leads forward to new technologies of rapid plant breeding; big data sets that include spatial and temporal landscape, soil, plant and weather data; and modern computing power applied to data analysis, agroecosystems modeling, and development and application of algorithms for decision-making in the near term and even in real-time.

The USDA-ARS is using the $\mathrm{G} \times \mathrm{E} \times \mathrm{M}$ paradigm and extending it with a post-harvest component that relates strongly to the first three components through the production system's relationship to yield quality, value, and thus socioeconomics $(\mathrm{S}): \mathrm{G} \times \mathrm{E} \times \mathrm{M} \times \mathrm{S}$. This paradigm is a key part of the USDAARS Long-Term Agroecosystem Research (LTAR) network research plan and is influencing other USDA-ARS national programs due to its power to guide research objectives to outcomes that are productive for stakeholders. Its power comes from taking into account the entire farming operation and the biophysical, economic, hydrologic, and social processes that affect crop productivity and sustainability in landscapes. These outcomes are naturally realized through PA because of its power to manage social and economic inputs in relation to the crop and environment in space and time to produce the crop yield and quality desired.

Because $\mathrm{G} \times \mathrm{E} \times \mathrm{M} \times \mathrm{S}$ research pulls in large amounts of interrelated environmental, genetic, management, and yield and quality data, it produces large data sets that are well suited for use in developing and testing simulation models and sub-models of several kinds. These include crop growth and yield, canopy and cover development, canopy reflectance-emittance-temperature, soil water balance and plant water uptake, energy and water balance, and so forth. While crop simulation models are notoriously unreliable for realtime, site-specific prediction (e.g., Webber et al., 2017), the use of near real-time data assimilation techniques can render them sufficiently accurate for management purposes, with the added advantage of being able to predict at least short- term future outcomes of applied management practices. When used with data assimilation, simulation models become the basis for DSS in PA (PA-DSS).

The accuracy and usefulness of simulation models is also improved through use of large data sets in multi-model comparison studies that explore the reasons for model inaccuracies and lead to model improvements (Liu et al., 2016; Webber et al., 2017). The Agricultural Model Intercomparison and Improvement Project (AgMIP, http://www.agmip.org/) is demonstrating how $\mathrm{G} \times \mathrm{E} \times \mathrm{M}$ datasets can lead to better understanding of model deficiencies and to model improvements (e.g., Maiorano et al., 2017; Pauli et al., 2017; Wang et al., 2017). This international research effort is strongly supported by UKaid (https://www.gov.uk/government/organisations/department-for-international-development) and the USDA, plus a variety of in-kind contributions by universities and other organizations internationally. Although not directly intended to support PA, the potential for AgMIP to improve PA-DSS is clear, particularly when improved models are combined with wireless sensor networks.

\section{THE ROLE OF IT, INCLUdING BIG DATA AND DATA STANDARDS FOR IT}

A primary problem with data that could be used in PADSS is that the available datasets either follow one of the many disparate data standards that exist today, or no accepted standard at all. For example, a datum as simple as soil water content has no meaning for crop management unless the user knows the depth and support volume of the reading, where and when the reading was taken, and the error limits of the datum. Similarly for crop canopy temperature data, which may be used to guide irrigation, a datum has no utility for that purpose unless the user knows whether the view was oblique (and at what angle) or nadir, its zenith angle, the time of day and day of year (sun angle effects), the area covered, the crop growth stage (for estimation of soil background interference), and the error limits. Beyond these data characteristics, users need to know the units of reported measurements; the metadata should include details of what was actually measured as well as what was reported. For example, many soil water sensors report volumetric water content, but none actually measure that; they measure either in the frequency or time domains, and knowing which domain can tell the user a lot about the data reliability. We are living in a data Babel, with shades of ancient Babylonia.

Application of data standards and data management plans are not keeping up with the internet cloud and the IOT that encompasses rapidly burgeoning wired and wireless sensor networks. Traditional sources of environmental data, including national weather networks (daily and subdaily), state and regional weather networks (daily and often subdaily), and hydrologic networks, are being surpassed in shear volume by new soil moisture networks, ecosystem and agroecosystem research networks, satellite platforms (biweekly to daily and subdaily), data fusion systems applied to satellite data, genomics and plant breeding programs, ad hoc and commercially proprietary sensing and data manipulation networks, etc.

Nonetheless, bright spots are emerging. The USDA-ARS LTAR network (https://ltar.ars.usda.gov/) has adopted data 
standards, including metadata standards, similar to those of the EPA and USGS. All U.S. federal government data standards are transitioning to the ISO suite of standards; ISO 19115 and its accompanying standards will replace prior standards as the official metadata standard for U.S. federal agencies. Data management planning is now required for all USDA-ARS research projects and for those funded by the USDA National Institute of Food and Agriculture (NIFA), as well as most other federal agencies. In the commercial sector, AgGateway (http://www.aggateway.org/), a nonprofit with more than 230 member companies, is a leader in PA data standards, including the Standardized Precision Ag Data Exchange (SPADE) project that is creating standards for data exchange between farm management systems and field equipment. An example is the Precision Ag Irrigation Language (PAIL) project that sets standards for field data used to develop irrigation management plans, operate irrigation equipment according to plans, and record the results (Ferreyra et al., 2017). AgGateway works with standards groups, including the business communications standards group GS1 (www.gs1.org), ASABE, the Agricultural Industry Electronics Foundation (AEF, www.aef-online.org), the Open Applications Group, Inc. (OAGi, oagi.org), and the USDA. The AgGateway Global Network is a non-profit recently formed to expand the successful AgGateway collaborative framework outside the US.

Data standards are key for interoperability of the sensors, IT systems, DSS, and SCADA systems that provide value in the agricultural market through mechanized PA. Standards are necessary in the rich, rapidly expanding and changing commercial and public sectors of data providers, interpreters, and users. Many potential partners inhabit this space: USDA, universities and cooperative extension, NOAA, NASA, USGS, DOE, the National Ecological Observatory Network (NEON, www.neonscience.org), the international community of atmospheric flux measurements (FLUXNET, fluxnet.ornl.gov), and many others. Turning potential partners into actual partners is the business of an ad hoc consortium of many players, including commodity groups, Farmers Business Network, Field to Market, Ag Data Coalition, AgGateway, Open Ag Data Alliance, private data integrators, and scientific and engineering societies such as ASABE and the American Society of Agronomy. Because a substantial part of these data are collected using systems that farmers own or are observations made using government resources that relate directly to privately owned land, issues of data ownership and privacy arise. Some U.S. farm groups have suggested that the USDA become the repository for such data, with appropriate privacy safeguards in place.

\section{FUTURE DIRECTIONS IN RESEARCH}

Almost every aspect of agricultural research has some application in PA. Geostatistical investigations of soil and plant attributes have long been established, but inclusion of temporal variations involves the application of ever more sophisticated models of plant growth and yield in response to the environment, management, and dynamics of water and nutrients. As noted previously, supercomputing holds promise for more deterministic simulation modeling approaches as well as for investigation of overall system behavior and identification of key variables through hypercube data analyses by means of network analysis methods.

AgMIP is one example of ongoing research needs in agricultural modeling (Rosenzweig et al., 2013). It has yielded new insights into the need for better simulation models as well as better data to support the development and testing of those models. For example, of 46 models tested, none was consistent in accurately simulating crop ET using high-quality data sets. Because ET is a key covariate with stress and yield, and one that is sensitive to short-term meteorological and long-term climate forcing, accurate ET estimates are of great importance. Because data are increasingly available at appropriate spatial and temporal resolutions for in-field management, the potential application to PA is clear.

Much is yet to be done in the development of sensors that can help identify plant biotic and abiotic stresses more accurately and quickly, at low cost, and with low power consumption. Assembling of these sensors into wireless networks that are themselves low cost and low power, yet reliable over long distances, is a continuing challenge but is greatly aided by technology coming out of the smart phone industry. New wireless data transmission protocols and commercial systems are announced almost weekly. Increasingly, agricultural research requires true interdisciplinary teams that include crop physiologists, soil scientists, computational scientists, proximal and remote sensing scientists, agricultural and biological engineers, and electrical engineers. Such teams will be needed to develop the next generation of more capable GPS-guided SCADA systems for PA.

Unmanned aircraft (UA), also known as unmanned aerial vehicles (UAV), are increasingly used for crop, pest, and irrigation management in the U.S. There were more than 1.1 million UA in the U.S. in 2016, and the FAA estimates that the number will at least triple by 2021. Commercial UA numbered approximately 42,000 in 2016 and are expected to number at least 442,000 by 2021 and may number as many as 1.6 million. The global UA market was valued at $\$ 13.9$ billion in 2017 and was projected by Verified Market Research to reach $\$ 49.4$ billion by 2025 . Rules and waivers are in place to allow UA use in agriculture. Low-cost UA are the result of a confluence of miniaturized electromechanical technologies similar to those that allow low-cost wireless sensor networks: microelectromechanical systems (MEMs) sensors (gyros, accelerometers, etc.), GPS modules, lowpower long-range (LoRa) radios, and multi-band cameras. Thanks to the competitive smart phone market, these technologies have become small, inexpensive, and powerful. Research progress is rapid in both university and private venues, aided by a community for sharing open-source code such as DIY Drones (http://diydrones.com/), and by 3-D printers for rapid prototyping and production, also with an open-source user community. Code for image stitching, orthogonal correction, and image processing is readily available. While imaging of fields is increasingly easy and inexpensive, even on a daily basis, there are continuing impediments to progress in delivering useful PA-DSS. These include sensor calibration, image correction, image analysis, and reliable decision support generation software.

In some instances, UA images are directly useful without complex processing, such as for showing problems with an 
irrigation system or a pest incursion. However, there are often shading, canopy structure, and other small-scale features in high-resolution imagery that affect image interpretation and model applications (Aboutalebi et al., 2018). The GRAPEX project, in partnership with Utah State University, is promoting UA technological advances for the vertical integration of remote sensing products for water management in complex agricultural settings (vineyards), from vine to regional scales (Kustas et al., 2018). For this purpose, multiple study sites that encompass different climates, soils, and grape varieties across the state of California are monitored and surveyed with UAs over areas that span from 120 ha to more than $2.5 \mathrm{~km}^{2}$. Preliminary results show promise for soil and canopy temperature retrieval and ET monitoring at vine canopy resolution (Nieto et al., 2018). A key component in developing robust assimilation and modeling approaches is dealing with the explosion of earth observations from multiple sources, including traditional satellite platforms, constellations of low-orbiting mini-satellites (CubeSats), and UA. Successful development has the potential of integrating a wealth of information at different spatial and temporal resolutions (Hassan-Esfahani et al., 2017).

Rapid prototyping supported by open-source hardware and software communities and companies is empowering scientists and engineers to develop and use sensors and wireless sensor networks that enable site-specific PA management. Arduino, BeagleBoard, Raspberry Pi, and other development platforms offer off-the-shelf hardware and software components for reading sensors, storing data, transmitting data wirelessly, and controlling devices (https:/www.arduino.cc/; https://beagleboard.org; https://www.raspberrypi.org). Successful examples include the wireless infrared thermometer sensors and sensor network that was commercialized from research prototypes based on the Zigbee platform by O'Shaughnessy et al. (2013) (SapIP-IRT, Dynamax, Inc., Houston, Tex., http://www.dynamax.com/products/crop-water-management/products/sapip-irt-infraredleaf-temperature). A current example is the wireless node and gateway system for soil water sensor data collection and wireless transmission developed by Schomberg and Thomp- son (Evett et al., 2018) using the Moteino MEGA, a wireless Arduino clone based on the Atmel ATMega1284P microcontroller, with a built-in LoRa transceiver $(868 / 915 \mathrm{MHz}$, https:/lowpowerlab.com/guide/moteino/). In this system, multiple nodes in the field each gather data from several soil water sensors and transmit the data using the LoRa radio to a gateway, which may be positioned at the end of the field, at a center-pivot irrigation system pivot point, or at another convenient location. The gateway retransmits the data over a cellular network connection to a web-based server. The data can be accessed via a web page for visualization or download. Researchers used the prototype system in a multistate on-farm research project to provide farmers near realtime information quantifying the effects of cover crops on soil water availability in corn cropping systems. The fieldproven prototypes were converted to commercial products within a year (fig. 6). Commercial versions increased the dependability by using surface-mounted processors, increasing the energy use efficiency, and integrating various circuit protection features.

While most wireless sensor networks operate with sensors above ground or embedded in the soil surface, there is increasing interest in sensing networks beneath the soil surface that can characterize the state and dynamics of physical, chemical, and biological aspects of the rhizosphere. The National Science Foundation-sponsored workshop on the "Subterranean MacroScope" focused on the many challenges involved in developing the needed sensors and communications networks (https://ime.uchicago.edu/subterranean_macroscope/). Disciplines involved include microbiology, genomics, biochemistry, plant and microbial physiology, physical chemistry, biophysics, soil physics, MEMS, microfluidics, and electrical engineering (Gupta et al., 2018). The workshop report identified three grand challenges:

- "Understand how the soil microbiome affects plant productivity, water and nutrient efficiency, and soil degradation.

- Create a new generation of accurate terrestrial ecosystem models; build C, N, and other nutrient cycling

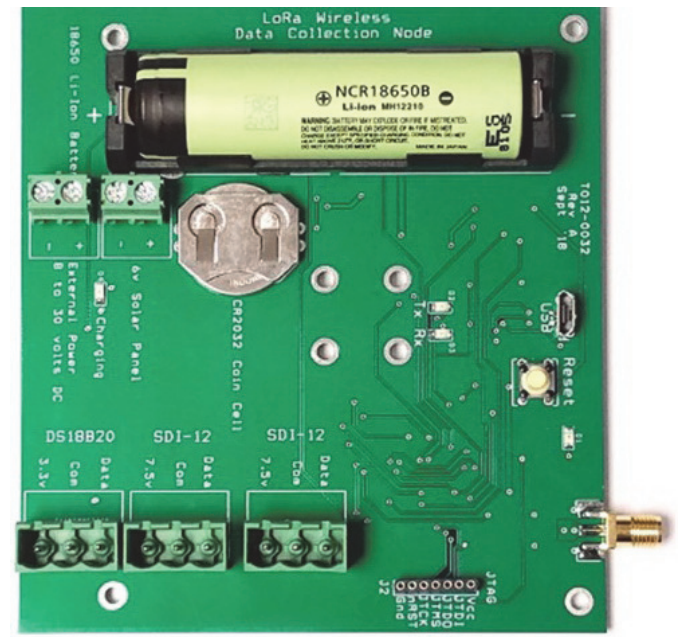

Figure 6. (Left) Revision 1.3 of the node prototype of Schomberg and Thompson. The small rectangular circuit board is the Moteino with LoRa radio. (Right) Commercial product based on the prototype (courtesy of Acclima, Inc., Meridian, Ida.). Integrated circuits are on the back side of the board to reduce the chance of short-circuiting during field sensor connections. 
models that offer predictive accuracy.

- Food security: understand that the root interface between the soil and the plant will have deep impacts for global sustainability, food security, and the environment."

While these grand challenges do not specifically address PA, it is important to understand that they are inherently problems that PA can address given the right combination of fundamental understanding of ecosystem processes, simulation models built on that understanding, and new subterranean wireless sensor systems that provide feedback and data assimilation to DSS based on the simulated and measured environment. Specific needs and opportunities for computer science and engineering research identified included: (1) sensors, sensor materials, and sensor device research; (2) micro/nano electronics research; (3) computer science research including new methods for sensor + data + model integration; and (4) wireless technology research for robust, fully buried, low-power sensing networks with high range and throughput.

\section{FUtURE DiReCtions IN TEChNOLOGY TRANSFER}

The commercial sector is increasingly involved in PA technology transfer because most PA technologies are too complex for on-farm development. Manufacturers are involved in every phase to produce and market sensors and sensor network systems, build SCADA systems into agricultural equipment, and produce and sell the equipment, often through dealers who take on the role of system support to varying degrees. This is also true in the development and marketing of new crop varieties that fit environmental and management scenarios and may be useful in PA planting systems. Commercial entities are increasingly active in the provision of actionable PA data and prescriptions to farmers. Companies such as Climate Corporation assemble data from multiple public sources (Landsat and other satellites, NOAA weather data, SSURGO soils data, etc.) and use large computing systems and statistical analysis to deliver recommendations. Many companies are providing aerial imagery at high resolution and in multiple visible and infrared bands to guide PA farming, although data interpretation and decision support are still works in progress.

Routine access to high-resolution ET mapping capabilities is being enabled through the OpenET project (https://etdata.org/). OpenET is a collaborative effort to implement an ensemble of Landsat-scale ET models on Google Earth Engine to facilitate rapid extraction of spatial and temporal water use information by stakeholders, allowing comparison of ET estimates from different modeling systems. Given the sparsity of high-quality ET ground validation stations across the U.S. and globally, a convergence-of-evidence approach comparing multiple models provides some information about data reliability. The initial focus of OpenET is on water management applications in the western U.S. As the toolkit matures, expansion to global coverage is envisioned in support of food and water security information needs.

NGOs are increasingly providing assistance for PA. Trade industry groups, such as the Irrigation Association, provide certified training at their annual meetings and via webinars. Scientific societies are involved through their meetings and outreach to the commercial sector. For example, the American Society of Agronomy is currently developing a PA specialization within its Certified Crop Advisor (CCA) training program that potentially applies to $>14,000$ crop consultants in North America.

Cooperative extension also plays a role. In the U.S., cooperative extension was the predominant paradigm for transferring technology to farmers in the 1900s. Today, extension is hampered by budget cuts, and to some degree is cut out of the picture due to the expanding role of commerce. However, there are still valid roles for extension in conducting public trials of new PA-DSS technologies, running publicly accessible demonstration farms, developing cost-benefit analyses of technology adoption, and publishing guides on new technologies.

\section{KEYS TO FUTURE SUCCESS}

A 2016 roundtable hosted by the USDA-ARS Office of International Research Programs and the International Society of Precision Agriculture identified ten keys to ensuring successful DSS for PA (Yost et al., 2018):

- Increase research documentation of PA outcomes.

- Enhance funding for PA research.

- Facilitate public-private partnerships.

- Develop more IP-neutral relationships between public and private research.

- Improve involvement of NGOs and others in PA research and application efforts.

- Generate more PA projects that encompass the goals of sustainable agriculture (economic profitability, environmental health, soil and economic equity).

- Achieve better balance between basic and applied research, short-term and long-term funding, and small versus large grants.

- Include more stakeholder involvement and retrospective assessments.

- Enhance research relevance to smallholder farms, especially internationally.

- Continue regular roundtable discussions.

To this list we could add: Develop the technological capabilities to deliver products via mobile phone apps. While these higher-level considerations are certainly important, useful PA-DSS and application technologies will emerge through the constant process of developing and testing sensors and sensing networks, IT systems and software, and control systems and application hardware, coupled with a robust and open user community.

\section{IMPLICATIONS FOR GLOBAL WATER SECURITY}

For a variety of reasons, modern PA has largely bypassed irrigation until recently, despite the fact that pressurized irrigation serves more than $65 \%$ of irrigated lands in the U.S., and moving irrigation systems serve $>57 \%$. These pressurized systems are all amenable to precision control. Today, every manufacturer of center-pivot irrigation systems provides some sort of variable-rate irrigation control in its basic system, at least sector-based control, also called speed control. Some provide more complete spatial control through a combination of radial and arc-wise control zones, and recent 
advances include single-nozzle control. However, decision support systems for precision irrigation application are just emerging, despite the use of decision support tools, GPS guidance, and on-the-go control in other areas of PA. Reasons for the lack of precision irrigation DSS include cost and timely availability of relevant spatial information of crop water needs and soil water status, lack of effective algorithms to convert data into reliable decisions, and lack of systems and subsystems integration into moving irrigation systems. This article documents recent advances that address all these gaps. The advent of the internet-of-things approach to wireless sensing systems has reduced the cost and increased the spatial density of proximal plant and soil sensing networks for use in irrigation DSS. Unmanned aircraft and multi-spectral camera systems have improved in utility, resolution, accuracy, and cost to the point that georeferenced data on plant growth, nutrient, and water status are now available to users outside the research realm. Improved, more plentiful, and complementary satellite observation systems have allowed data experts to develop data fusion software systems that produce daily evapotranspiration maps at $30 \mathrm{~m}$ resolution, which are already being used by large commercial growers of high-value crops and by irrigation districts. In addition, research and development of variable-rate irrigation algorithms, DSS, and sensing subsystems is now jumping from the research realm to adoption by major irrigation system manufacturers. The relevance to global water security is clarified by field testing, which shows that variable-rate irrigation DSS consistently increases crop water productivity while resulting in greater yields than farmers' normal practices.

\section{CONCLUSIONS}

The fundamentals of PA were employed thousands of years ago in manual fashion, but it is only since about 1980 that GPS technology has allowed easy and efficient mapping of soil, landscape, and crop properties that can be used to guide precision application of practices and inputs. Originally conceived as a passive and indirect process of first measuring and mapping the state variables of interest and then using the map to make decisions about PA practices, PA today involves a mix of the older paradigm and a newer paradigm of active and direct response to variations in crop and environmental properties detected using sensor networks, often wireless, and often on-the-go. The definition of PA has been greatly expanded by the availability of inexpensive, wireless, and often mobile sensors, coupled with modern IT, sophisticated algorithms for data processing and decision support, and computer control systems guiding machinery to apply practices and inputs. Renewed focus on sensors for soil physical, chemical, biological and microbiological properties in the rhizosphere, and ways to wirelessly transmit data out of the soil, promise to engender the next generation of sensing systems for guiding PA. The great increase in data from private and public sources is opening new avenues for PA research, development, and application. Simulation model improvements are ongoing, and future models promise to be competent enough to be the internal engines of PA-DSS, particularly if they are made self-correcting through assimilation of data from the plethora of internet-of-things sensors. A key problem in developing robust assimilation and modeling approaches is how to deal with the explosion of earth observations from multiple sources, including traditional satellite platforms, constellations of low-orbiting mini-satellites (CubeSats), and UA. Because most PA technology will be manufactured and made available to farmers through retailers, technology transfer is steadily moving from the public sector to the private sector, but there remains a place for public sector technology transfer, both from research to commercial production and by extension services field testing, demonstrating, and analyzing the economics of the new technologies. The fundamental aim of PA is more efficient and effective use of resources, whether manmade or natural. Water is one of these resources, but wise water use cannot be implemented without consideration of the other resources and their management. As evidenced by several examples in this article, the implications of PA for global water security are more efficient use of water resources, reducing the water needed to produce a unit of yield. These PA technologies offer policymakers a key tool for developing policies for reduced water use while maintaining farmer productivity and profitability.

\section{ACKNOWLEDGEMENTS}

This material is based on work that is supported by the USDA National Institute of Food and Agriculture under Award No. 2016-67021-24420. The work reported in this article was also accomplished as part of a Cooperative Research and Development agreement between the USDAARS and Valmont Industries, Inc., Valley, Nebraska (Agreement No. 58-3K95-0-1455-M). The Viticulture, Chemistry, and Enology Division of E. \& J. Gallo Winery has provided financial, logistical, and personnel support for GRAPEX. Additional financial support for this research comes from the NASA Applied Sciences - Water Resources Program (Grant No. NNH17AE39I).

\section{REFERENCES}

Aboutalebi, M., Torres-Rua, A. F., Kustas, W. P., Nieto, H., Coopmans, C., \& McKee, M. (2018). Assessment of different methods for shadow detection in high-resolution optical imagery and evaluation of shadow impact on calculation of NDVI, and evapotranspiration. Irrig. Sci., 37(3), 407-429.

https://doi.org/10.1007/s00271-018-0613-9

Anderson, M. C., Kustas, W. P., Alfieri, J. G., Gao, F., Hain, C., Prueger, J. H., ... Chavez, J. (2012). Mapping daily evapotranspiration at Landsat spatial scales during the BEAREX '08 field campaign. Adv. Water Resour., 50, 162-177. https://doi.org/10.1016/j.advwatres.2012.06.005

Anderson, M., Gao, F., Knipper, K., Hain, C., Dulaney, W., Baldocchi, D., ... Medellin-Azuara, J. (2018). Field-scale assessment of land and water use change over the California Delta using remote sensing. Remote Sensing, 10(6), 889. https://doi.org/10.3390/rs10060889

Aubert, B. A., Schroeder, A., \& Grimaudo, J. (2012). IT as enabler of sustainable farming: An empirical analysis of farmers' adoption decision of precision agriculture technology. Decision Support Syst., 54(1), 510-520. 
https://doi.org/10.1016/j.dss.2012.07.002

Bronson, K. F., White, J. W., Conley, M. M., Hunsaker, D. J., Thorp, K. R., French, A. N., ... Holland, K. H. (2017). Active optical sensors in irrigated durum wheat: Nitrogen and water effects. Agron. J., 109(3), 1060-1071. https://doi.org/10.2134/agronj2016.07.0390

Cammalleri, C., Anderson, M. C., Gao, F., Hain, C. R., \& Kustas, W. P. (2013). A data fusion approach for mapping daily evapotranspiration at field scale. Water Resour. Res., 49(8), 4672-4686. https://doi.org/10.1002/wrcr.20349

Cammalleri, C., Anderson, M. C., Gao, F., Hain, C. R., \& Kustas, W. P. (2014). Mapping daily evapotranspiration at field scales over rainfed and irrigated agricultural areas using remote sensing data fusion. Agric. Forest Meteorol., 186, 1-11. https://doi.org/10.1016/j.agrformet.2013.11.001

Erickson, B., \& Lowenberg-Deboer, J. (2017). Making the turn toward decision agriculture: 2017 dealership survey. CropLife, 180(6), 8-14.

Evett, S. R., Anderson, S. K., Casanova, J. J., \& Schwartz, R. C. (2015). Soil water and conductivity sensing system. U.S. Patent No. US 8,947,102 B1.

Evett, S. R., O'Shaughnessy, S. A., \& Peters, R. T. (2014). Irrigation scheduling and supervisory control and data acquisition system for moving and static irrigation systems. U.S. Patent No. 8,924,031.

Evett, S. R., Schomberg, H. S., Thompson, A., Schwartz, R. C., O'Shaughnessy, S. A., \& Andrade, M. A. (2018). Water in the Cloud: A new system for field water monitoring with Cloud data access. Proc. Irrigation Association Show and Education Conf. Technical Session. Retrieved from https://www.irrigation.org/IA/Resources/Technical-PaperLibrary.aspx

Ferreya, R. A., Berne, D., \& Hillyer, C. (2017). PAIL supports precision irrigation. Irrigation Today (July 2017), 24-25. Retrieved from http://www.modernpubsonline.com/0A406ys/IrrigationTodayJul 17/html/index.html?page $=24$

Griffin, T., Miller, N., \& Torrez, C. (2016). Precision agriculture technology and obsolescence. KSU-AgEcon-TG-2016.1. Manhattan, KS: Kansas State Universit,y Department of Agricultural Economics.

Gupta, S., Rice, C. W., Ghosh, M., Foster, I., Izaurralde, R. C., Mohamed, A., \& Evett, S. R. (2018). NSF Workshop Report: The subterranean macroscope: Sensor networks for understanding, modeling, and managing soil processes.

Hassan-Esfahani, L., Ebtehaj, A. M., Torres-Rua, A., \& McKee, M. (2017). Spatial scale gap filling using an unmanned aerial system: A statistical downscaling method for applications in precision agriculture. Sensors, 17(9), article 2106. https://doi.org/10.3390/s17092106

Hatfield, J. L., \& Walthall, C. L. (2015). Meeting global food needs: Realizing the potential via genetics $\times$ environment $x$ management interactions. Agron. J., 107(4), 1215-1226. https://doi.org/10.2134/agronj15.0076

Knipper, K. R., Kustas, W. P., Anderson, M. C., Alfieri, J. G., Prueger, J. H., Hain, C. R., ... Nieto, H. (2018). Evapotranspiration estimates derived using thermal-based satellite remote sensing and data fusion for irrigation management in California vineyards. Irrig. Sci., 37(3), 431-449. https://doi.org/10.1007/s00271-018-0591-y

Kustas, W. P., Anderson, M. C., Alfieri, J. G., Knipper, K., TorresRua, A., Parry, C. K., ... Hain, C. (2018). The grape remote sensing atmospheric profile and evapotranspiration experiment. Bull. American Meteorol. Soc., 99(9), 1791-1812. https://doi.org/10.1175/bams-d-16-0244.1

Liu, B., Asseng, S., Muller, C., Ewert, F., Elliott, J., Lobell, D., ...
Zhu, Y. (2016). Similar estimates of temperature impacts on global wheat yield by three independent methods. Nature Clim. Change, 6, 1130-1138. https://doi.org/10.1038/nclimate3115

Lyons, D. J., Heinemann, P. H., Schupp, J. R., Baugher, T. A., \& Liu, J. (2015). Development of a selective automated blossom thinning system for peaches. Trans. ASABE, 58(6), 1447-1457. https://doi.org/10.13031/trans.58.11138

Maiorano, A., Martre, P., Asseng, S., Ewert, F., Muller, C., Rotter, R. P., ... Zhu, Y. (2017). Crop model improvement reduces the uncertainty of the response to temperature of multi-model ensembles. Field Crops Res., 202, 5-20.

https://doi.org/10.1016/j.fcr.2016.05.001

Nieto, H., Kustas, W. P., Torres-Rua, A., Alfieri, J. G., Gao, F., Anderson, M. C., ... Prueger, J. H. (2018). Evaluation of TSEB turbulent fluxes using different methods for the retrieval of soil and canopy component temperatures from UAV thermal and multispectral imagery. Irrig. Sci., 37(3), 389-406. https://doi.org/10.1007/s00271-018-0585-9

Ondoua, R. N., \& Walsh, O. (2017). Precision agriculture advances and limitations: Lessons to the stakeholders. Crops Soils, 50(4047).

O’Shaughnessy, S. A., Evett, S. R., \& Colaizzi, P. D. (2015). Dynamic prescription maps for site-specific variable-rate irrigation of cotton. Agric. Water Mgmt., 159, 123-138. https://doi.org/10.1016/j.agwat.2015.06.001

O’Shaughnessy, S. A., Evett, S. R., Andrade, A., Workneh, F., Price, J. A., \& M. Rush, C. (2016). Site-specific variable-rate irrigation as a means to enhance water use efficiency. Trans. ASABE, 59(1), 239-249. https://doi.org/10.13031/trans.59.11165

O’Shaughnessy, S. A., Evett, S. R., Colaizzi, P. D., \& Howell, T. A. (2013). Wireless sensor network effectively controls centerpivot irrigation of sorghum. Appl. Eng. Agric., 29(6), 853-864. https://doi.org/10.13031/aea.29.9921

Pauli, D., White, J. W., Andrade-Sanchez, P., Conley, M. M., Heun, J., Thorp, K. R., ... Gore, M. A. (2017). Investigation of the influence of leaf thickness on canopy reflectance and physiological traits in upland and pima cotton populations. Front. Plant Sci., 8(1405). https://doi.org/10.3389/fpls.2017.01405

Rosenzweig, C., Jones, J. W., Hatfield, J. L., Ruane, A. C., Boote, K. J., Thorburn, P., ... Winter, J. M. (2013). The Agricultural Model Intercomparison and Improvement Project (AgMIP): Protocols and pilot studies. Agric. Forest Meteorol., 170, 166182. https://doi.org/10.1016/j.agrformet.2012.09.011

Schimmelpfennig, D. (2016). Farm profits and adoption of precision agriculture. Economic Research Report No. 2017. Washington, DC: USDA Economic Research Service.

Schwartz, R. C., Evett, S. R., Anderson, S. K., \& Anderson, D. J. (2016). Evaluation of a direct-coupled time-domain reflectometry for determination of soil water content and bulk electrical conductivity. Vadose Zone J., 15(1). https://doi.org/10.2136/vzj2015.08.0115

Semmens, K. A., Anderson, M. C., Kustas, W. P., Gao, F., Alfieri, J. G., McKee, L., ... Vélez, M. (2016). Monitoring daily evapotranspiration over two California vineyards using Landsat 8 in a multi-sensor data fusion approach. Remote Sensing Environ., 185, 155-170. https://doi.org/10.1016/j.rse.2015.10.025

Shearer, S. A., \& Pitla, S. K. (2014). Precision planting and crop thinning. In S. Young, \& F. Pierce (Eds.), Automation: The future of weed control in cropping systems (pp. 99-124). Dordrecht, The Netherlands: Springer. https://doi.org/10.1007/978-94-007-7512-1_6

Snyder, C. (2016). Suites of 4R nitrogen management practices of sustainable crop production and environmental protec-tion. Issue Review Ref. No. 16057. International Plant Nutrition Institute. 
Sposari, M., \& Flis, S. (2017). 4R framework implementation: Precision ag adoption by farmers and dealers. Crops Soils, 50(5), 24-26. https://doi.org/10.2134/cs2017.50.0507

Sun, L., Anderson, M. C., Gao, F., Hain, C., Alfieri, J. G., Sharifi, A., ... McKee, L. (2017). Investigating water use over the Choptank River watershed using a multisatellite data fusion approach. Water Resour. Res., 53(7), 5298-5319. https://doi.org/10.1002/2017wr020700

USDA. (2014). 2012 Census of agriculture. United States summary and state data, Vol 1 - Geographic area series - Part 51, AC-12A-51. Washington, DC: USDA National Agricultural Statistics Service.

USDA. (2015). 2012 Census of agriculture. Specialty crops, Vol 2 Subject series - Part 8, AC-12-S-8. Washington, DC: USDA National Agricultural Statistics Service.

USDA. (2017). Soil Survey Geographic Database (SSURGO). Washington, DC: USDA Natural Resources Convervation Service. Retrieved from https://catalog.data.gov/dataset/soilsurvey-geographic-ssurgo-database-for-various-soil-surveyareas-in-the-united-states-

Wang, E., Martre, P., Zhao, Z., Ewert, F., Maiorano, A., Rotter, R. P., ... Asseng, S. (2017). The uncertainty of crop yield projections is reduced by improved temperature response functions. Nat. Plants, 3, article 17102. https://doi.org/10.1038/nplants.2017.102

Webber, H., Martre, P., Asseng, S., Kimball, B., White, J., Ottman, M., ... Ewert, F. (2017). Canopy temperature for simulation of heat stress in irrigated wheat in a semi-arid environment: A multi-model comparison. Field Crops Res., 202, 21-35. https://doi.org/10.1016/j.fcr.2015.10.009

Xia, T., Kustas, W. P., Anderson, M. C., Alfieri, J. G., Gao, F., McKee, L., ... Sanchez, L. (2016). Mapping evapotranspiration with high-resolution aircraft imagery over vineyards using oneand two-source modeling schemes. Hydrol. Earth Syst. Sci., 20(4), 1523-1545. https://doi.org/10.5194/hess-20-1523-2016

Yang, Y., Anderson, D. J., Gao, F., Hain, C., Kustas, W., Meyers, T., ... Yang, Y. (2017a). Impact of tile drainage on evapotranspiration in South Dakota, USA, Based on high spatiotemporal resolution evapotranspiration time series from a multisatellite data fusion system. J. Selected Topics Appl. Earth Obs. Remote Sensing, 10(6), 2550-2564. https://doi.org/10.1109/JSTARS.2017.2680411

Yang, Y., Anderson, M. C., Gao, F., Hain, C. R., Semmens, K. A., Kustas, W. P., ... Sun, G. (2017b). Daily Landsat-scale evapotranspiration estimation over a forested landscape in North Carolina, USA, using multi-satellite data fusion. Hydrol. Earth Syst. Sci., 21(2), 1017-1037. https://doi.org/10.5194/hess-211017-2017

Yang, Y., Anderson, M. C., Gao, F., Wardlow, B., Hain, C. R., Otkin, J. A., ... Dulaney, W. (2018a). Field-scale mapping of evaporative stress indicators of crop yield: An application over Mead, NE, USA. Remote Sensing Environ., 210, 387-402. https://doi.org/10.1016/j.rse.2018.02.020

Yang, Y., Anderson, M., Gao, F., Hain, C., Noormets, A., Sun, G., ... Sun, L. (2018b). Investigating impacts of drought and disturbance on evapotranspiration over a forested landscape in North Carolina, USA, using high spatiotemporal resolution remotely sensed data. Remote Sensing Environ., 111018. https://doi.org/10.1016/j.rse.2018.12.017

Yost, M. A., Sudduth, K. A., Walthall, C. L., \& Kitchen, N. R. (2018). Public-private collaboration toward research, education, and innovation opportunities in precision agriculture. Prec. Agric., 20(1), 4-18. https://doi.org/10.1007/s11119-018-9583-4 